Georgia State University

ScholarWorks @ Georgia State University

GHPC Briefs

Georgia Health Policy Center

$10-23-2018$

\title{
School-Based Mental Health
}

Georgia Health Policy Center

Follow this and additional works at: https://scholarworks.gsu.edu/ghpc_briefs

\section{Recommended Citation}

Georgia Health Policy Center, "School-Based Mental Health" (2018). GHPC Briefs. 95.

https://scholarworks.gsu.edu/ghpc_briefs/95

This Article is brought to you for free and open access by the Georgia Health Policy Center at ScholarWorks @ Georgia State University. It has been accepted for inclusion in GHPC Briefs by an authorized administrator of ScholarWorks @ Georgia State University. For more information, please contact scholarworks@gsu.edu. 


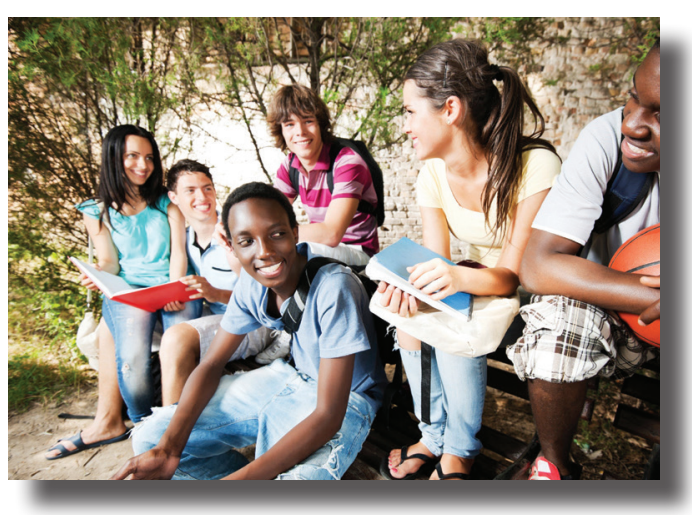

\section{SCHOOL-BASED MENTAL HEALTH}

\section{October 2018}

\section{BACKGROUND}

Mental health concerns are common among today's school-age children, with an estimated one in five children under 18 years of age having a diagnosable mental health disorder. ${ }^{1-3}$ Although most mental disorders can be managed with appropriate treatment, the vast majority of children needing services - an estimated $75 \%$ to $80 \%$ - do not receive them. ${ }^{4-6}$ The presence of untreated mental disorders can create significant challenges, particularly in the academic environment. ${ }^{7}$ If unaddressed, these problems can impair academic performance, decrease school attendance, and cause behavioral concerns in the learning environment. ${ }^{8}$

School-based mental health (SBMH) programs provide a continuum of mental health services to students and families in the school setting. By placing mental health professionals in schools, SBMH programs increase access to needed mental health services; promote earlier identification of and intervention for mental health needs; and foster collaboration between mental health providers, school systems, and community stakeholders.

\section{CONCEPTUAL FRAMEWORK}

One conceptual model used to guide SBMH is the three-tiered intervention framework, where provision of mental health services fall into three distinct levels (see Figure 1).6, 8, 11, 21

- Tier I programs and activities are generalizable to an entire school and are implemented schoolwide.

- Tier II programs and services target students at risk of developing mental health concerns.

- Tier III services are tailored to a small population of high-risk students and are more intensive interventions.

Figure 1: Three-Tiered Approach to SBMH

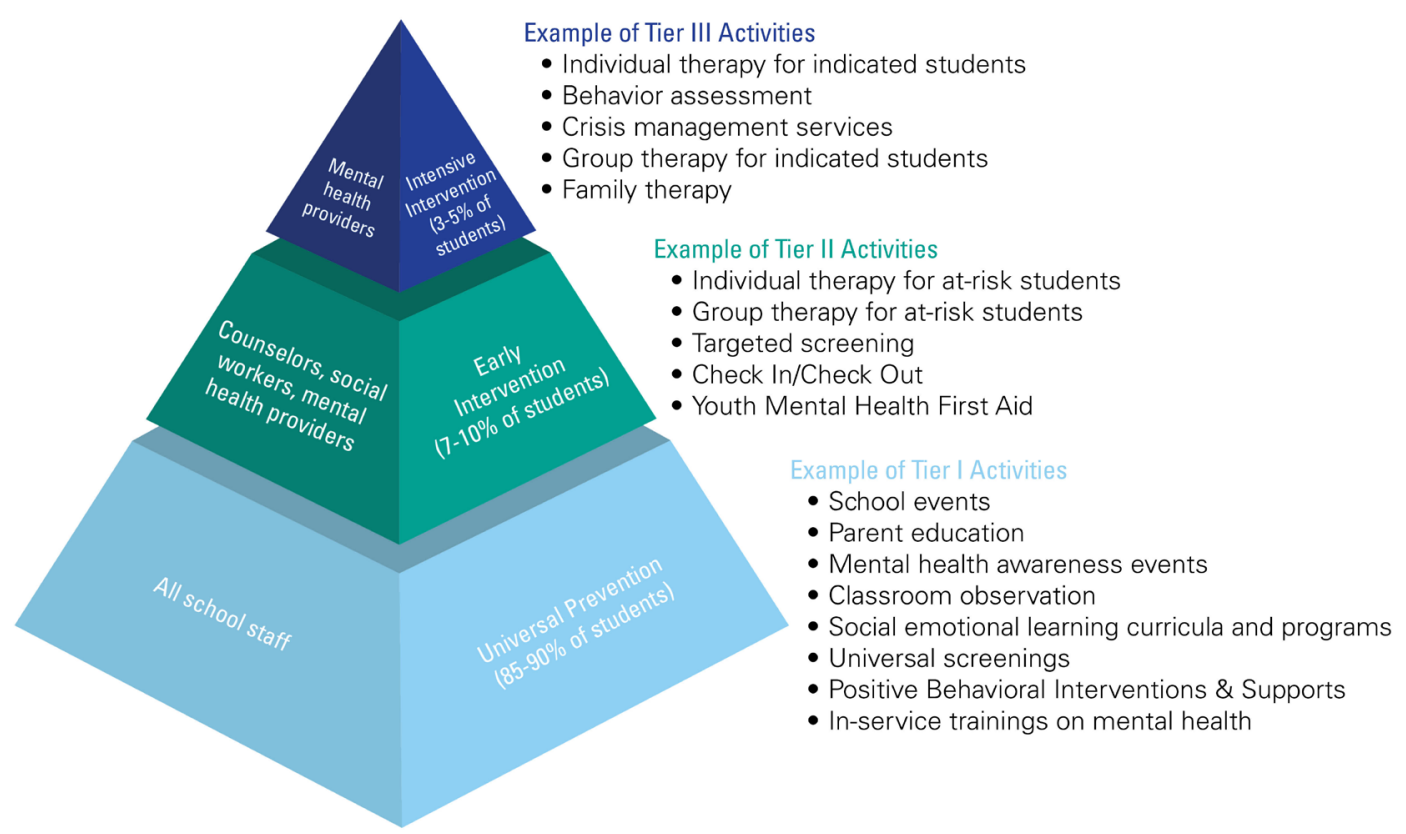

\section{CENTER OF EXCELLENCE FOR}

CHILDREN'S BEHAVIORAL HEALTH

integrating research, policy, and practice 


\section{PROVIDERS}

SBMH professionals can provide services at one or multiple schools. Depending on the program, SBMH providers are either employed by mental health providers that are contracted to provide services within schools or employed directly by schools, school systems, or school districts.7,11

\section{REFERRALS}

Students may be referred to SBMH services by an adult, such as a school social worker, teacher, or counselor, or can be self-referred. ${ }^{79}$ Referrals generally go through a specified process, such as the one depicted in Figure 2.

A teacher may notice a student having behavior problems and refer him/her to the school counselor. The counselor would then determine if that student should be referred on to the mental health professional.

Figure 2: Example Referral Process

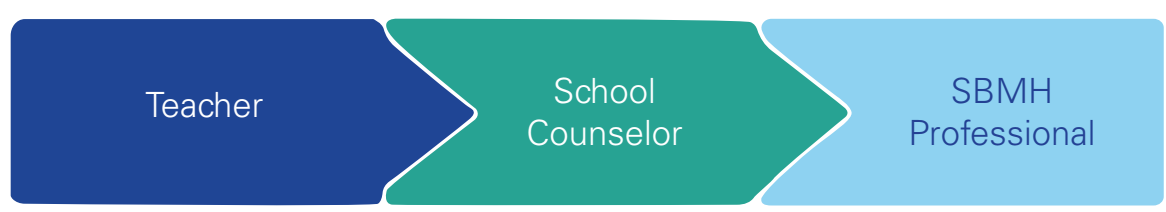

\section{SERVICES}

SBMH programs offer students and their families a broad spectrum of mental health services at little to no cost. $11,21-23$

Figure 3: Sampling of SBMH Services

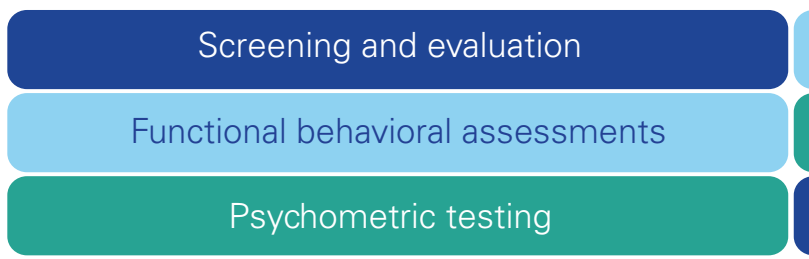

Referrals to community providers

Medication management

Counseling (individual, small group, or family)

\section{BENEFITS}

SBMH programs lead to a variety of positive outcomes for students, their families, and schools. ${ }^{9-20}$

Figure 4: Positive Outcomes Associated With SBMH Programs

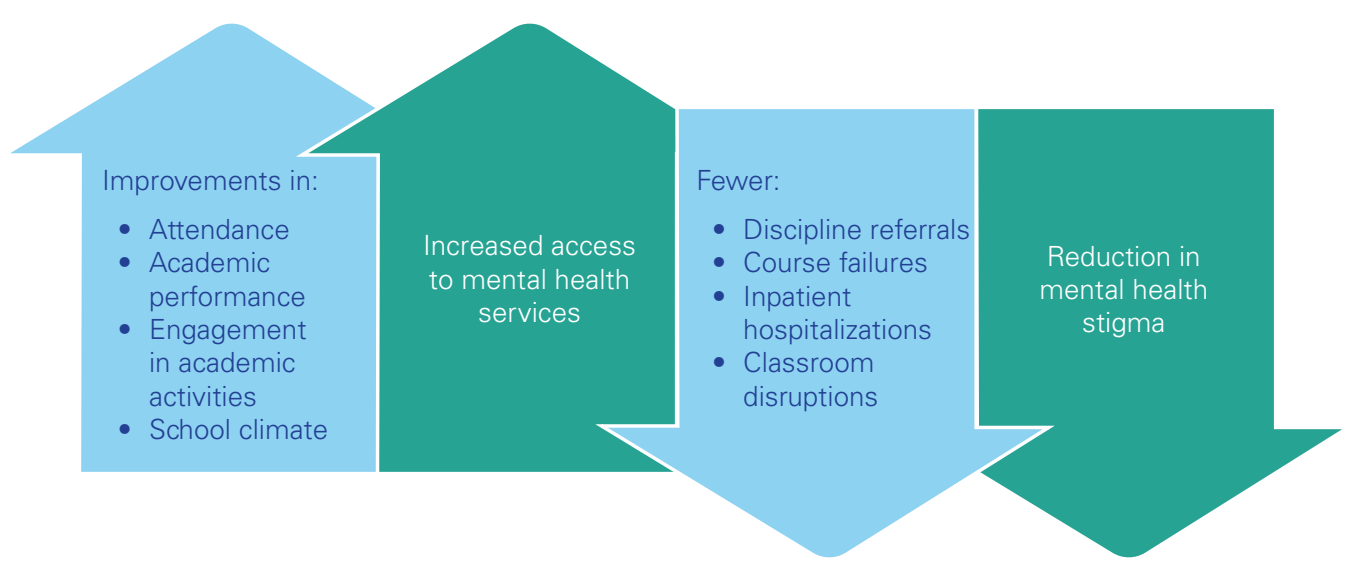

The information presented in this brief comes from two sources: a review of literature on $\mathrm{SBMH}$ and interviews with SBMH program implementers across the nation, as well as one national SBMH expert. References are available online. Please find the issue brief online at https://gacoeonline.gsu.edu/files/2018/10/COE-Brief-References_Final_10.2018.pdf
CENTER OF EXCELLENCE FOR

CHILDREN'S BEHAVIORAL HEALTH

integrating research, policy, and practice

Center of Excellence for Children's Behavioral Health Georgia Health Policy Center

55 Park Place NE, 8th floor • Atlanta, GA 30303 404.413.0075 (phone) • 404.413.0316 (fax) gacoeonline.gsu.edu 